University of Nebraska - Lincoln

DigitalCommons@University of Nebraska - Lincoln

2016

\title{
INFLUENCE OF WRITING ABILITY AND COMPUTATION SKILL ON MATHEMATICS WRITING
}

Sarah R. Powell

Michael Hebert

Follow this and additional works at: https://digitalcommons.unl.edu/specedfacpub

Part of the Special Education and Teaching Commons

This Article is brought to you for free and open access by the Department of Special Education and Communication Disorders at DigitalCommons@University of Nebraska - Lincoln. It has been accepted for inclusion in Special Education and Communication Disorders Faculty Publications by an authorized administrator of DigitalCommons@University of Nebraska - Lincoln. 


\title{
INFLUENCE OF WRITING ABILITY AND COMPUTATION SKILL ON MATHEMATICS WRITING
}

\begin{abstract}
A B S T RACT
Mathematics standards expect students to communicate about mathematics using oral and written methods, and some high-stakes assessments ask students to answer mathematics questions by writing. Assumptions about mathematics communication via writing include $(a)$ students possess writing skill, $(b)$ students can transfer this writing skill to mathematics writing, and $(c)$ mathematics writing is representative of a mathematics knowledge. We conducted a study in which we investigated the connections among general writing ability, mathematics computation skill, and mathematics writing. With 155 fourth-grade students in two regions of the United States, we administered a measure of essay writing, a measure of mathematics computation skill, and two mathematics-writing prompts. Results indicate moderate correlations among general writing ability, computation skill, and mathematics writing. Additionally, general writing ability and computation skill are significantly related to mathematics-writing outcomes.
\end{abstract} Sarah R. Powell UNIVERSITY OF TEXAS AT AUSTIN

Michael A. Hebert

UNIVERSITY OF NEBRASKA-LINCOLN

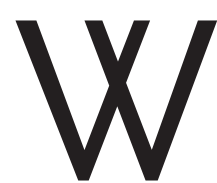

RITIN G is often described as a form of language that allows students to communicate ideas, thoughts, feelings, and knowledge (Graham \& Perin, 2007; Shanahan, 2006). Over the past decade, writing has become a more utilized method for communicating about mathematics. The National Council of Teachers of Mathematics (NCTM, 200o) describes

THE ELEMENTARY SCHOOL JOURNAL

Volume 117, Number 2. Published online November 3, 2016

(C) 2016 by The University of Chicago. All rights reserved. o013-5984/2016/11702-0007\$10.00 
communication as "an essential part of mathematics" (p. 60), and the NCTM lists communication as one of the five process standards for effective mathematics instruction. The NCTM expresses that written communication about mathematics is not often the focus of mathematics education, and therefore students require instruction on using the language of mathematics to express ideas, both oral and written. Additionally, the standards for mathematical practice of the Common Core (National Governors Association Center for Best Practices \& Council of Chief State School Officers, 2010) suggest students be able to construct viable arguments, critique the mathematics reasoning of others, explain how to solve problems, use clear definitions and vocabulary, and communicate precisely to others. Writing about mathematics may be one method for students to meet these standards.

Before we proceed, we comment briefly on terminology. In this study, we examined the mathematics writing of fourth-grade students. That is, we asked students to write about two mathematics scenarios, one based around a word problem requiring addition, subtraction, and multiplication computation and one based around fraction concepts of numerator and denominator. Throughout this manuscript, we refer to the students' writing about these scenarios as mathematics writing. We focus on the written organization and mathematical content of the mathematics writing. In this manuscript, mathematics writing does not indicate writing numerals, writing or rewriting expressions or equations, writing in expanded form, or writing about time. In this introduction, we briefly discuss the importance of general writing ability and computation skill. Then, we discuss mathematics writing, and how students write in informal and formal ways. Next, we review current research about mathematics writing. Finally, we introduce the purpose and research questions for the present study.

\section{Importance of Writing Ability and Mathematics Performance}

According to The Nation's Report Card, only $27 \%$ of eighth-grade students in the United States score at or above "proficient" on the National Assessment of Education Progress writing assessment (National Center for Education Statistics, 2012), with $20 \%$ of students scoring "below basic." Twelfth-grade students perform similarly, and across grades, females outperform males. As students who are less proficient with writing typically have more difficulty in school and have fewer postsecondary opportunities (Graham, 2006), it is necessary to develop students into effective writers. It is promising that, with instruction, the writing quality of elementary students improves dramatically (Graham, McKeown, Kiuhara, \& Harris, 2012), and this is true for students with and without disabilities (Lienemann, Graham, Leader-Janssen, \& Reid, 2006). Reading ability is often linked to writing ability (Hooper, Roberts, Nelson, Zeisel, \& Fannin, 2010; How \& Larkin, 2013; Jenkins, Johnson, \& Hileman, 2004), yet much less is known about a link between mathematics performance and writing.

Similar to writing, proficiency with mathematics is important for success in school and adulthood. For example, mathematics in kindergarten was the single best predictor of academic achievement 5 years later (Claessens, Duncan, \& Engel, 2009). Lee (2012) determined that mathematics performance during elementary and secondary school predicted access to college and completion of college. Examining the impact of mathematics performance into adulthood, Bynner and Parsons 
(1997) concluded that students with lower mathematics performance in school had fewer job opportunities as adults and made less money than adults who performed well with mathematics during school, although the authors found the difference may also be attributed to other factors, such as reading achievement, general grade point average, or family income.

\section{Mathematics Writing}

Combining writing and mathematics may enable students to increase both writing skill and mathematics performance (Thompson, 2010). Many teachers understand the need for writing to be a part of the mathematics curriculum, but teachers find it difficult to combine writing and mathematics (Fukawa-Connelly \& Buck, 2010). Mathematics writing can help teachers understand conceptual misconceptions and procedural mistakes; mathematics writing may help students organize thinking, connect mathematical ideas, and develop a deeper and richer understanding of mathematics (Cross, 2009; Thompson, 2010). Teachers may encourage students to write about mathematics in informal or formal ways.

Informal mathematics writing. For many students, the opportunity for mathematics writing comes in the form of journal or diary writing (Fello \& Paquette, 2009; Lynch-Davis, 2011; Yang, 2005) or through activities such as letter writing to a pen pal (Lynch \& Bolyard, 2012). For example, Sanders (2009) asked high school students in a geometry class to produce journal entries about concerns or areas of confusion. Students also worked on test corrections by writing why or how they answered incorrectly. At the middle school level, Baxter, Woodward, and Olson (2005) used mathematics journals for an entire school year with lowerperforming students. Students used journals to explain their thinking about mathematics, demonstrate conceptual understanding, and solve problems using drawings, symbols, and words. Over the course of the year, the journals permitted students to become more active learners, to ask the teacher for help without hesitation, and to use drawings to demonstrate an understanding of mathematical concepts. The mathematics journal writing provided students with an additional method for communication about mathematics. Also with journals, Kostos and Shin (2010) asked second-grade students to complete mathematics problems about grouping, multidigit addition, and multidigit subtraction. Teachers encouraged students to write step-by-step explanations in journals for each problem. After journal writing for 5 weeks, students provided better explanations about mathematics procedures and vocabulary. Teachers learned of misconceptions that required additional instruction or reteaching.

Journal or diary writing, or other informal writing methods such as exit slips, creating class books or alphabet books, or think-write-shares (Thompson, 2010; Wilcox \& Monroe, 2011), provide teachers with methods for encouraging students to write about mathematics. Often, however, mathematics writing is quite informal and teachers only provide brief feedback, when they provide feedback at all (LynchDavis, 2011). Students do not receive regular practice for formal mathematics writing with informal mathematics writing (Bossé \& Faulconer, 2008). Without specific journal prompts provided by the teacher and appropriate feedback (Lynch-Davis, 2011), informal mathematics writing may not adequately prepare students for the 
rigors of formal mathematics writing (e.g., mathematics writing on high-stakes assessments).

Formal mathematics writing. On some high-stakes state assessments and two of the new assessments associated with the Common Core, students write about mathematics to answer mathematics questions. Most questions at the elementary grades often ask students to explain their answer. Student writing is scored compared to a rubric specifically designed to assess both the writing process and mathematical understanding, and these rubrics often include graduated score patterns where students earn more points for more in-depth written explanations. On performance tasks developed to assess Common Core standards, several assessment items move beyond asking students to explain their work. Students may be asked to write about whether a hypothetical student's work is correct or incorrect, whether teams are likely to have enough time to play another game, how to know areas are equal in size, or which purchase option would be cheaper.

Current research. To understand how teachers could help students respond to written questions about mathematics (e.g., explain your work, write about which purchase option is cheaper), we conducted an informal review of current mathematicswriting research. Over the past 2 decades, researchers have conducted hundreds of studies and analyses about writing (Juzwik et al., 2006), yet very few empirical studies focus on using writing to express mathematical ideas. In one example, Bicer, Capraro, and Capraro (2013) worked with 96 middle-school students in an after school program. Half of students used writing when working on mathematics problem solving, and the other half practiced problem solving without writing. At posttest, students who received writing practice embedded within mathematics demonstrated greater cognitive understanding of mathematical processes and answered more problems correctly. The researchers provided no explicit instruction on mathematics writing.

In a slightly different way, Seo (2009) worked with 13 high school students, and the students completed four mathematics-writing prompts. Two prompts were introduced in English class and two in mathematics class. Seo (2009) learned that students responded with writing differently based on whether the audience was the English or mathematics teacher. For the mathematics teacher, students used equations and fewer written words. For the English teacher, students used written sentences to explain ideas along with the equations. These research studies contribute knowledge about student mathematics writing, yet do not provide information about how to effectively teach mathematics writing for high-stakes situations. Many authors provide suggestions for teaching mathematics writing (e.g., Burns 2004; Carter, 2009; Ediger, 2006; Fernsten, 2007; McCarthy, 2008), but these suggestions are based on writing research or teaching experiences without validation through high-quality research.

\section{Assumptions of Mathematics-Writing Tasks and Assessments}

The assessment of mathematics skills through writing rests on three assumptions. One, students have the writing skills necessary to develop a cohesive and constructive written essay. Two, students can transfer their knowledge of writing to mathematics-writing tasks and communicate their knowledge of mathematical concepts and procedures in writing. Three, and perhaps most importantly, stu- 
dents' ability to write about mathematics provides an accurate portrayal of their mathematical abilities. These assumptions, however, may not be valid.

First, given the limited instruction that teachers provide about writing (Gilbert \& Graham, 2010), we cannot assume that all students have foundational writing skills necessary to develop a cohesive and constructive essay. As we already expressed, data from the National Center for Education Statistics reveal that less than onethird of students in the United States have mastered the skills necessary for "proficient," or grade-level-appropriate writing (2012). The vast majority of students scored at the "basic" level or below, which denotes only partial mastery of writing skills needed at each grade. Although these data were not examined for mathematics writing specifically, the data provide an indication that the first assumption may not hold.

Second, it is unlikely that students can transfer general writing skills to writing about mathematics. This is a very complex assumption, as it involves the combination of both mathematics and writing skills. Research on writing suggests that more effective writers understand the purpose of writing, the writing audience, and how to plan for writing (e.g., Hough, Hixson, Decker, \& Bradley-Johnson, 2012). Also, more effective writers use grammar, structure, vocabulary, and semantics competently (e.g., Correnti, Matsumara, Hamilton, \& Wang, 2013; Wakely, Hooper, de Kruif, \& Swartz, 2006). The nature of the descriptions for these skills seems general and, thus, generalizable. However, current research (Graham, Hebert, Sandbank, \& Harris, 2016) only shows a low to moderate correlation among writing genres (i.e., story, personal narrative, opinion essay, and informative text). Coffman (1966) found that a minimum of five writing tasks was needed to reliably assess the writing achievement of typically developing students, Huang (2008) reported that three writing tasks were needed, and Graham et al. (2016) reported that five to eleven were needed, depending on the measure and criteria. In addition to pure writing concerns, students must interpret mathematics presented in the abstract form (i.e., numerals and symbols) and within scenarios presented with words to complete mathematics-writing tasks. Prior research indicates that students have difficulty with the translation of mathematics into the abstract format (e.g., Driver \& Powell, 2015; Sherman \& Bisanz, 2009) and mathematics problems embedded within word problems (e.g., Swanson, Jerman, \& Zheng, 2008). Thus, it is questionable whether general writing skill can be generalized to mathematics or whether students can communicate their mathematics knowledge in writing.

Third, it is also uncertain whether students' ability to write about mathematics provides an accurate portrayal of their mathematical abilities. Kostos and Shin (2010) indicated that students can communicate about mathematics with writing. However, the authors do not explain the mechanisms through which students do this, and no research has investigated how students make this connection.

\section{Purpose and Exploratory Questions of the Present Study}

Despite the background research presented, there is little research on the influence of writing and mathematics skills on mathematics writing. Given that mathematics standards expect students to communicate about mathematics and that some high-stakes assessments ask students to answer mathematics questions in 
an open-response format using writing, it is necessary for students to have the ability to effectively write about mathematics. It may be that students require explicit instruction to learn how to write about mathematics. Based on a survey of the research, most literature related to mathematics writing provides suggestions or strategies for mathematics writing without an empirical base. In order to understand the mathematics writing of elementary students, we conducted an exploratory investigation about the connections among general writing ability, mathematics computation skill, and mathematics writing to understand how general writing and mathematics computation performance may influence mathematics writing.

The questions that guided this exploratory study were as follows:

1. What are the relationships among general writing ability, mathematics computation performance, and mathematics writing? We hypothesized significant correlations between general writing ability and mathematics writing as well as computation and mathematics writing.

2. What are the influences of general writing ability and mathematics computation performance on mathematics writing, when controlling for gender and region? We hypothesized that students with stronger writing ability and computational skill would demonstrate better mathematics writing.

3. What is the influence of whole number computation and rational number computation skill on mathematics writing? We hypothesized that stronger skill with whole number computation would lead to improved mathematics writing about word problems. In the same way, stronger skill with rational numbers would lead to improved mathematics writing about fractions.

\section{Method}

\section{Participants}

Participants $(N=155)$ were sampled from eight fourth-grade classrooms in four schools in two states in the United States. Four classrooms $(n=76)$ were located in a rural school district in the plains region, and the other four classrooms $(n=79)$ came from a suburban school district in the southwestern region. The plains district had a student population consisting of 1.4\% African American, $0.8 \%$ Asian, $11.6 \%$ Hispanic, $81.6 \%$ White, and $4.6 \%$ other. In the plains district, $44.2 \%$ of students qualified for reduced-price and/or free lunch. The southwestern district had a student population consisting of 3.9\% African American, 5.5\% Asian, $23.9 \%$ Hispanic, $62.6 \%$ White, and $4.2 \%$ other. The percentage of students who qualified for reduced-price and/or free lunch was 18.9. To describe the students, we gathered the sex and age of each student. We gathered race and disability status information by classroom. Table 1 displays demographic information by site.

\section{Measures}

We administered four measures to all students: general essay writing, mathematics computation, word-problem mathematics writing, and fraction mathematics writing. 
Table 1. Demographic Information

\begin{tabular}{|c|c|c|c|c|c|c|}
\hline \multirow[b]{2}{*}{ Variable } & \multicolumn{2}{|c|}{$\begin{array}{c}\text { Plains } \\
(n=76)\end{array}$} & \multicolumn{2}{|c|}{$\begin{array}{l}\text { Southwestern } \\
\quad(n=79)\end{array}$} & \multicolumn{2}{|c|}{$\begin{array}{c}\text { Total } \\
(N=155)\end{array}$} \\
\hline & $n$ & $(\%)$ & $n$ & $(\%)$ & $n$ & $(\%)$ \\
\hline Males & 39 & （51.3） & 34 & $(43.0)$ & 73 & $(47.1)$ \\
\hline \multicolumn{7}{|l|}{ Race: } \\
\hline African American & 2 & $(2.6)$ & 3 & $(3.8)$ & 5 & $(3.2)$ \\
\hline Asian & o & $(.0)$ & 5 & $(6.3)$ & 5 & $(3.2)$ \\
\hline Hispanic & 8 & $(10.5)$ & 9 & $(11.4)$ & 17 & $(11.0)$ \\
\hline White & 66 & $(86.8)$ & 59 & $(74.7)$ & 125 & $(80.6)$ \\
\hline Other & o & (.o) & 3 & $(3.8)$ & 3 & $(1.9)$ \\
\hline \multirow[t]{2}{*}{ School-identified disability } & 9 & $(11.8)$ & 15 & $(19.0)$ & 24 & $(15.5)$ \\
\hline & $M$ & $(S D)$ & $M$ & $(S D)$ & $M$ & $(S D)$ \\
\hline Age & $10 \mathrm{yr}, 4 \mathrm{mo}$ & $(4 \mathrm{mo})$ & $10 \mathrm{yr}, 3 \mathrm{mo}$ & $(4 \mathrm{mo})$ & $10 \mathrm{yr}, 4 \mathrm{mo}$ & $(4 \mathrm{mo})$ \\
\hline
\end{tabular}

General essay writing. To measure students' general writing ability, we administered the Essay Composition subtest of the Wechsler Individual Achievement Test—3rd edition (WIAT-III, Psychological Corp., 2009). On Essay Composition, the examiner read the essay prompt aloud, and then students had 10 minutes to write about their favorite game and provide at least three reasons why the game is their favorite. We scored Essay Composition utilizing a rubric of theme development and text organization provided by the WIAT-III. Students earned up to 2 points for a thesis statement in the introduction, up to 2 points for a conclusion statement, and o to 5 points for the number of paragraphs. A paragraph included at least two punctuation marks and was separated using line spacing or indentation. Students also earned o to 5 points for each novel transition expression following punctuation (e.g., another, second, finally). Students earned o to 3 points for each reason of why they like a game and an additional o to 3 points for an elaboration for each reason. Maximum score was 20. Following WIAT-III instructions, we also counted the total number of separate words written. Median reliability, as reported by Breaux (2010), is .85 for fourth-grade students assessed in the spring.

Mathematics computation. We measured computational skill with the Math Computation subtest of the Wide Range Achievement Test 4 (WRAT4; Wilkinson \& Robertson, 2006). We selected the WRAT4 Math Computation subtest because it is brief, can be administered in a whole-class setting, and because mathematics computation is a strong predictor of overall mathematics competence (e.g., Jordan, Kaplan, \& Hanich, 2002; Mabbott \& Bisanz, 2008). The examiner read directions aloud and students worked independently. Students had 15 minutes to answer 40 written computation problems of increasing difficulty. According to the WRAT4 administration manual, students answering four or fewer written problems correctly are administered 15 oral arithmetic problems. In the current study, no students required administration of the oral arithmetic section of Math Computation. Students answering more than four written problems correctly were given 15 points without administration of the oral arithmetic problems. Students received one point for each correct answer. The maximum possible score was 55 . As reported by Wilkinson and Robertson (2006), median reliability for students in fourth grade is .92. We 
converted raw scores to percentile ranks and standard scores using the spring of fourth-grade normative data provided by Wilkinson and Robertson (2006).

Word-problem mathematics writing. We first assessed mathematics writing using a researcher-developed Math Writing Word Problem (MW-WP) prompt. We designed this prompt (see Fig. 1) to assess computation skill within a wordproblem scenario as fourth-grade mathematics standards adopted by most states in the United States require students to solve "multistep word problems . . . using the four operations" (National Governors Association Center for Best Practices \& Council of Chief State School Officers, 2010, p. 29). In the MW-WP prompt, a hypothetical student, "Sam," solved a word problem in four steps. Step A involved multiplication of single-digit numbers, but this step is unnecessary because the information is within the word problem. In step B, Sam added two-digit numbers $(\$ 20+\$ 20)$, but completing step B was incorrect. The word problem indicated a total of only $\$ 20$, so Sam should not have added an additional \$20. Step C involved addition of monetary values. This was the correct procedure, but Sam made

Anna mowed 4 lawns. She was paid $\$ 5$ for mowing each lawn. With her mowing money of $\$ 20$, Anna goes to the magic shop. She decides to buy a magic wand and a magic hat. How much money does Anna have left after buying the wand and hat?

Here's how Sam solves the problem:

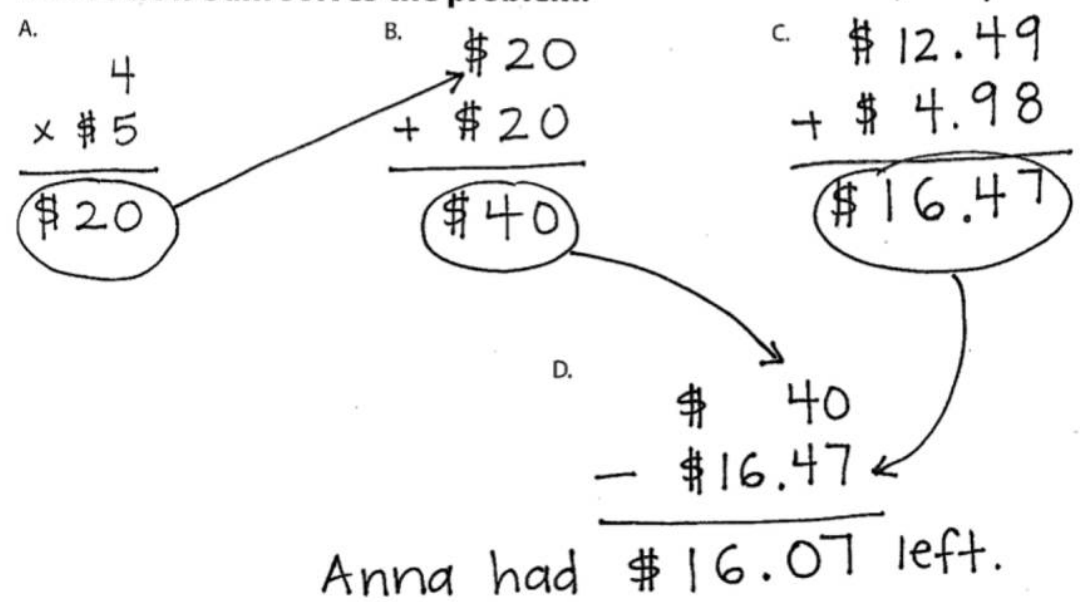

\footnotetext{
Sam made several mistakes in different steps of the problem. Write about the mistakes that Sam made, and write about how would you solve the problem correctly.
}

Figure 1. Math writing word problem (MW-WP) prompt. 
a regrouping mistake in the ones place. Step D required subtraction. Sam used the incorrect minuend (from step B) and the incorrect subtrahend (from step C). The student also procedurally lined up the numbers incorrectly for the subtraction problem. Thus, Sam arrived at an incorrect answer. To administer the prompt, the examiner read the prompt aloud while the students looked over Sam's work. Then, students wrote for 10 minutes about Sam's mistakes and how to solve the problem correctly.

For comparison purposes, we developed a scoring system for MW-WP based on the scoring rubric for WIAT-III Essay Composition. All MW-WP essays were scored for Organization and Content. In terms of Organization and similar to the WIAT-III, students earned up to 2 points for a thesis statement in the introduction, up to 2 points for a conclusion statement, and o to 5 points for the number of paragraphs. Students also earned o to 5 points for each novel transition expression. Maximum score for MW-WP Organization was 14.

To understand the ways students wrote about mathematics Content, we created our own scoring rubric. The Content score was loosely based on the WIAT-III scoring, but instead of scoring for reasons and elaborations, we scored for mathematics errors identified, elaborations about the errors, and inclusion of the corrected answers or explanations of how the answer could be corrected. Students could score points in these categories for each step of Sam's work. In step A, students earned up to 3 points for identifying math is correct, identifying the step is unnecessary, and explaining why it's unnecessary. We scored step B similarly with a 3 point maximum. In step $C$, students earned up to 4 points for identifying the operation is correct, identifying the answer is incorrect, elaborating about the mistake (i.e., regrouping error), and correcting the answer. In step D, students earned up to 9 points for identifying the incorrect minuend and subtrahend, providing the correct minuend and subtrahend, identifying incorrect place value setup, elaborating about place value, correcting place value, identifying incorrect subtraction, elaborating on incorrect subtraction, providing correct subtraction, and correcting the answer (i.e., writing the correct answer). Please note that we did not explicitly ask students to provide the correct answer; we prompted students (as seen in Fig. 1) to "write about how you would solve the problem correctly." Maximum score for MW-WP Content was 19. In addition to the Organization and Content scoring, we counted the total words written. We counted each numeral (e.g., 4, 9) and symbol (e.g., $\$,+,=$ ) as a unique word. Maximum score for the MW-WP was 33. Coefficient alpha (Cronbach's $\alpha$ ) for this sample was .73. (See Table A1 in the Appendix for means and standard deviations for each item on the MW-WP rubric, as well as information on the item-to-total correlations and how Cronbach's $\alpha$ would change without a specific item.)

Fraction mathematics writing. In a similar way, we assessed writing about fractions using a researcher-developed Math Writing Fraction (MW-FR) prompt. This prompt (see Fig. 2) aligned with fourth-grade mathematics standards about "using visual fraction models" for representing fractions (National Governors Association Center for Best Practices \& Council of Chief State School Officers, 2010, p. 30). We used the three models of fractions (i.e., area, length, set; Van de Walle, Karp, \& Bay-Williams, 2013). In the MW-FR prompt, a hypothetical teacher asked four students ("Alex, Bo, Cole, and Deb") to draw the fraction three-fifths. Alex drew a 


\section{Mr. Pack asks his students to draw the fraction $\frac{3}{5}$. Here are the drawings of four students.}

Alex

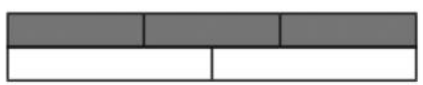

Bo



Cole

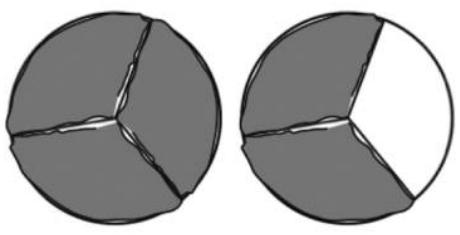

Deb

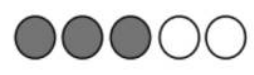

\section{Some students made mistakes in their drawings. First, write down the names of all the students who made mistakes. Then, choose one student you would like to help. Write about their mistake and how you would help them solve the problem correctly.}

Figure 2. Math writing fractions (MW-FR) prompt.

rectangular area model with five unequal-sized boxes; three were shaded. Bo drew a length model with eight equal-sized boxes; three were shaded. Cole drew a circular area model with two circles; each circle was divided equally into thirds; five parts were shaded. Deb drew a set model with five circles; three circles were shaded. To administer the prompt, the examiner reviewed the prompt while students looked at the work of the hypothetical students. Students then wrote for 10 minutes about the hypothetical students who made mistakes and how they would help them solve the problem correctly.

Similar to the MW-WP, we developed a scored MW-FR based on the Essay Composition of the WIAT-III. MW-FR Organization scoring was identical to MWWP with a maximum score of 14 for an introduction, conclusion, paragraphs, and/ or transition words. Scoring differed from MW-WP on the mathematics content, but was similarly based on students' ability to identify errors, elaborate about the errors, and include the corrected answers. Students earned up to 7 points for identifying the students who made (or did not make) mistakes and identifying a student they wanted to help. With reference to Alex, students earned up 5 points for identifying that the drawing has five parts, recognizing that Alex shaded three, explaining that parts are unequal sizes, and correcting Alex's mistake via writing and/or draw- 
ing. With reference to Bo, students earned up to 5 points for identifying that Bo drew eight parts, identifying that Bo shaded three parts, discussing the incorrect denominator, and correcting Bo's mistake via writing and/or drawing. Finally, with reference to Cole, students earned up to 5 points for identifying incorrect use of whole number representations, identifying that Cole shaded five parts, identifying that Cole used the incorrect denominator, and correcting Cole's mistake via writing and/ or drawing. Maximum score for content was 22 for a combined maximum score for MW-FR of 36. Additionally, we counted the total words written. Coefficient alpha (Cronbach's $\alpha$ ) for this sample was .69. (See Table A1 in the Appendix for means, standard deviations, item-to-total correlations, and changes to Cronbach's $\alpha$ for each item on MW-FR.)

Interrater reliability. Five raters (the two authors and three graduate students in education) scored the assessments and assisted in creating the database. Two scorers experienced with the WIAT-III rubric scored the Essay Composition writing samples for all students. For training purposes, the raters first double scored a random sample of 10 writing samples. Following training, one rater scored all of the remaining writing samples, and a second rater scored a random sample of $25 \%$ of the essays for reliability purposes; interrater reliability, calculated as the percentage of agreement, was $90 \%$. Only the scores from the first rater were used in the analyses. For the WRAT4 Math Computation, a first rater entered student responses for individual items (e.g., 91, 1/8) directly into a spreadsheet. Scores for all 155 students were converted to correct and incorrect values by the first author using spreadsheet commands. A second rater scored a random sample of $20 \%$ of the WRAT 4 assessments; interrater reliability, calculated as the percentage of agreement, was $99 \%$.

For the MW-WP assessment, the two authors trained together and double scored the writing samples from one classroom and resolved disagreements through discussion. Because this was a newly developed assessment that had never been scored before, scoring standards were developed and agreed upon during training. Next, the two authors each acted as the primary rater for half of the remaining writing samples. A graduate assistant then acted as a secondary rater and scored a random sample $20 \%$ of the essays for reliability purposes; interrater reliability, calculated as the percentage of agreement, was $92 \%$ based on item-by-item agreement. Only the scores from the primary rater were used in the analyses. The training and scoring procedures for the MW-FR assessment were the same as those for the MW-WP sample, although the assessments from a different classroom were used as the training passages. Interrater reliability, calculated as percentage of agreement, was $94 \%$.

\section{Procedure}

Testing occurred in two 30-minute whole-class testing sessions administered within the same week in May or June. WIAT-III Essay Composition and WRAT4 Math Computation were administered in the first session. MW-WP and MW-FR were administered in the second session in a counterbalanced order across classrooms. Examiners were the two authors (with graduate degrees in special education) and a graduate student with a master's degree in school psychology. All 
examiners were trained to administer the measures by following the same testadministration procedures and reading from the same test-administration script.

\section{Data Analysis}

Data analyses were conducted using STATA/SE 12 (StataCorp., 2011). Correlations were used to examine the relationships between variables to investigate question 1. Multilevel models were examined for questions 2 and 3. However, the ICCs were less than .03 for the classroom-level variance for both models. Therefore, ordinary least squares was used in the hierarchical regression models used to answer questions 2 and 3 .

Hierarchical regression procedures. Two hierarchical regression analyses were used to investigate the predictive value of essay writing skill and mathematics computation skill as well as gender and region as control variables, on the mathematicswriting scores. One analysis was conducted for the MW-FR outcome score, and one analysis was conducted on the MW-WP score. For each outcome, we included gender and region into model 1. In models 2 and 3, we added the WIAT-III Essay Composition and WRAT4 Math Computation scores individually before including them both in model 4 . This helped us determine whether each variable explained unique variance in each of the two outcome measures. Changes in $R^{2}$ values across the models were examined to evaluate whether each aspect of the students' composing behavior explained a unique and significant portion of the variance in the mathematicswriting scores for each model. Additionally, the contributions of the predictor variables were compared across the two models to determine if there was consistency across the types of mathematics writing.

We checked regression assumptions for each of the models prior to making inferences. We had to reject the assumption of normality of the residuals for the regression of MW-WP scores on writing skill, computational skill, gender, and region. To account for this issue, we did a square-root transformation of the dependent variable, and the normality assumption was met. However, the significance of the independent variables and the $R^{2}$ values was not affected. Therefore, we decided to present the results of the original model for ease of interpretability.

Heteroskedasticity was examined using the Breusch-Pagan/Cook-Weisburg test. The final models returned chi-square value(s) of $1.06(p=0.304)$ for the MW-WP Total Score, and $2.27(p=0.132)$ for the MW-FR Total Score. The models were then examined for overly influential data points. Studentized residuals were examined for outliers, leverage, and influence. We calculated Cook's D, DFITS, and DFBETA statistics, as well as graphic displays of the data. Graphic plots showing the leverage by residuals squared were examined for observations that were unusually high on both measures. Partial-regression plots were also examined for each of the variables in the model. One potential outlier was found for MWWP, and two potential outliers were identified for MW-FR, but the observations were not found to be overly influential. Further examination of the specific participants revealed that one student scored very low on WIAT-III Essay Composition, but average on WRAT4 Math Computation and higher than might be expected on MW-WP and MW-FR. Because the research questions relate to the direct comparison of the influence of writing skill and computational skill on these dependent 
variables, eliminating these data points might bias the results in a substantive way. Therefore, they were kept in the model.

Normality of the variance inflation factors (VIF) and tolerance factors indicated that there were no multicollinearity problems in any of the models. Finally, the assumption of linearity was examined. For the comparison, the standardized residuals from the regression with each of the independent variables augmented componentplus-residual plots to compare ordinary regression lines with lowess smoothed lines. None of the plots showed a violation of the linearity assumption.

Variables used in the regression models. The standard scores for WIAT-III Essay Composition and WRAT4 Math Computation were converted to $z$-scores to aid in the interpretability of the intercept in the regression models that apply to model 2. Alternatively, individual items relating to specific mathematics skills (i.e., whole number computation, rational number computation) were identified from WRAT 4 Math Computation, and then the raw scores for items were summed to create a total raw score for whole number computation skill and a total raw score for rational number computation. The raw scores for whole number computation and rational number computation were then used in the regression models that apply to model 3. The raw scores for MW-WP and MW-FR were used in all analyses, as these assessments have not been normed.

\section{Results}

The results for WIAT-III Essay Composition, WRAT4 Math Computation, and the MW-WP and MW-FR assessments have been compiled by region, as well as the overall sample, to compare potential differences by region. Table 2 displays means and standard deviations for the assessments. The scores for both MW-WP and MW-FR are compiled and presented by subscores for Organization and Content, as well as Total Score.

Table 2. Means and Standard Deviations of Measures

\begin{tabular}{|c|c|c|c|c|c|c|}
\hline \multirow[b]{2}{*}{ Variable } & \multicolumn{2}{|c|}{$\begin{array}{l}\text { Plains } \\
(n=76)\end{array}$} & \multicolumn{2}{|c|}{$\begin{array}{l}\text { Southwestern } \\
\quad(n=79)\end{array}$} & \multicolumn{2}{|c|}{$\begin{array}{c}\text { Total } \\
(N=155)\end{array}$} \\
\hline & $M$ & $(S D)$ & $M$ & $(S D)$ & $M$ & $(S D)$ \\
\hline WIAT-III Essay Composition & 108.53 & $(13.44)$ & 106.75 & $(13.18)$ & 107.62 & $(13.29)$ \\
\hline $\mathrm{WRAT}_{4}$ Math Computation & 115.34 & $(9.42)$ & 108.62 & $(11.24)$ & 111.92 & $(10.89)$ \\
\hline \multicolumn{7}{|l|}{ MW-WP: } \\
\hline Organization & 1.72 & $(1.44)$ & 1.86 & $(1.47)$ & 1.79 & $(1.45)$ \\
\hline Content & 3.47 & $(2.67)$ & 4.42 & $(3.15)$ & 3.95 & $(2.95)$ \\
\hline Total & 5.20 & $(3.39)$ & 6.27 & $(4.08)$ & 5.75 & $(3.79)$ \\
\hline \multicolumn{7}{|l|}{ MW-FR: } \\
\hline Organization & 1.67 & (1.41) & 1.81 & (1.56) & 1.74 & $(1.48)$ \\
\hline Content & 7.58 & $(2.70)$ & 6.90 & $(3.33)$ & 7.23 & $(3.05)$ \\
\hline Total & 9.25 & $(3.56)$ & 8.71 & $(4.24)$ & 8.97 & $(3.92)$ \\
\hline
\end{tabular}




\section{Comparisons by region}

Comparisons of the standard scores for WRAT4 Math Computation revealed significant differences between the participants by region $(t=4.03, p<.001)$. Participants in the plains region had significantly higher scores than students in the southwestern region. There were also significant differences on the MW-WP Content score $(t=-2.01, p=.046)$, indicating that students in the southwestern region scored significantly higher than students in the plains region. Although there seem to be some minor differences in ethnicity categories across the samples, results of a chi-square analysis indicated that the differences were not statistically significant $\left(\chi^{2}=8.59, p=.072\right)$.

There were no differences between participants by region for the WIAT-III Essay Composition, MW-WP Organization, MW-FR Total Score, MW-FR Organization, and MW-FR Content at the $p=.05$ level. However, results were significant for the MW-WP Total Score at the $p=.10$ level, indicating that there may be some potentially important differences to keep in mind between the regions on this dependent variable; similar to the MW-WP Content score, the mean for the students in the southwest was higher than the mean for students in the plains.

\section{Correlations between Measures}

To examine the relationships among general writing ability, computational skill, and mathematics writing, we examined correlations between each of the assessments. The correlation matrix is presented in Table 3. Scores for Organization, Content, and Total Score were included for the MW-WP and MW-FR to examine whether there were potentially important relationships between the standardized measures of writing ability and computation skill and specific aspects of the mathematics-writing tasks.

All correlations were significant at $p<.01$. The correlation between WIAT-III Essay Composition and WRAT4 Math Computation was small $(r=.26)$. The WIAT-III Essay Composition scores and WRAT4 Math Computation scores were correlated with both of the mathematics-writing measures. The correlations among the WIAT-III Essay Composition, MW-WP, and MW-FR were moderate, ranging from .40 to .48. Results from $\mathrm{WRAT}_{4}$ Math Computation were more strongly correlated with both of the mathematics-writing Total Scores than was

Table 3. Correlation Matrix

\begin{tabular}{lcccccccc}
\hline & 1 & 2 & 3 & 4 & 5 & 6 & 7 & 8 \\
\hline 1. WIAT-III Essay Composition & 1.00 & & & & & & & \\
2. WRAT4 Math Computation & .2623 & 1.00 & & & & & & \\
3. MW-WP Organization & .4452 & .2778 & 1.00 & & & & & \\
4. MW-WP Content & .2982 & .4783 & .4121 & 1.00 & & & \\
5. MW-WP Total & .4028 & .4830 & .7039 & .9373 & 1.00 & & \\
6. MW-FR Organization & .3581 & .2520 & .3341 & .2876 & .3520 & 1.00 & \\
7. MW-FR Content & .3358 & .5095 & .3208 & .4199 & .4501 & .4275 & 1.00 \\
8. MW-FR Total & .3958 & .4917 & .3760 & .4355 & .4834 & .7111 & .9396 & 1.00 \\
\hline \multicolumn{7}{c}{ Note--WIAT-III = Wechsler Individual Achievement Test (3rd ed.); WRAT4 } & Wide Range Achievement Test (4th ed.); \\
MW-WP = Math Writing Word Problem; MW-FR = Math Writing Fractions.
\end{tabular}


WIAT-III Essay Composition. This indicates that computation skill was a stronger indicator of success on these mathematics-writing prompts than writing skill.

Correlation analyses of mathematics-writing component scores revealed that the WIAT-III Essay Composition was more strongly correlated with Organization than Content for both MW-WP and MW-FR. Alternatively, WRAT4 Math Computation was more strongly correlated with the Content than the Organization for both MW-WP and MW-FR. These results indicate that students' writing ability and computation skill are both significantly related to mathematics writing, but they each may contribute more strongly to different aspects of mathematics writing.

\section{Influences of General Writing Ability and Computation Skill}

We used regression models to examine the influence of writing ability and computation skill on both of the mathematics-writing tasks. The Total Scores for the mathematics-writing tasks were used as the dependent variable in the models. Gender, region, and $z$-scores for the WIAT-III Essay Composition (i.e., writing ability) and WRAT4 Math Computation (i.e., computation skill) were included as independent variables. Because there were significant differences between the regions on one of the primary dependent variables used in the models, we elected to include as an additional independent variable to determine whether there were differences by region. We also controlled for gender. We included the interactions between computation skill and writing ability into a final model for each outcome. However, the interaction was not a significant predictor for either outcome.

Word-problem mathematics writing. Results for the MW-WP outcome are presented in Table 4. Model 1 results revealed that the control variables explained $6 \%$ of the variance in story-writing quality, $F(2,152)=4.66, p=.011$. The addition

Table 4. Hierarchical Multiple Regression Analyses Predicting Mathematics-Writing Scores from General Writing Ability and Computation Knowledge

\begin{tabular}{|c|c|c|c|c|c|c|c|c|c|c|c|c|}
\hline \multirow[b]{2}{*}{ Variable } & \multicolumn{3}{|c|}{ Model 1} & \multicolumn{3}{|c|}{ Model 2} & \multicolumn{3}{|c|}{ Model 3} & \multicolumn{3}{|c|}{ Model 4} \\
\hline & $b$ & $S E$ & $t$ & $b$ & $S E$ & $t$ & $b$ & $S E$ & $t$ & $b$ & $S E$ & $t$ \\
\hline \multicolumn{13}{|l|}{ MW-WP outcome: } \\
\hline Intercept & $4 \cdot 48^{* * *}$ & .51 & 8.71 & $4.81^{* * *}$ & .48 & 10.00 & $3.73^{* * *}$ & .43 & 8.68 & $4.03^{* * *}$ & .42 & 9.57 \\
\hline Gender & $1.46^{\star *}$ & .60 & 2.45 & .59 & .58 & 1.02 & $1.56^{* * *}$ & .49 & 3.18 & $.99^{*}$ & .50 & 2.00 \\
\hline Region & .95 & .60 & 1.61 & $1.23^{* *}$ & .55 & 2.22 & $2.33^{* * *}$ & .51 & 4.52 & $2.34^{* * *}$ & .49 & 4.74 \\
\hline WIAT-III Essay Composition & & & & $1.48^{* * *}$ & .29 & 5.12 & & & & $.95^{\star * *}$ & .26 & 3.69 \\
\hline $\mathrm{WRAT}_{4}$ Math Computation & & & & & & & $2.23^{* * *}$ & .26 & 8.65 & $1.97^{* * *}$ & .26 & 7.66 \\
\hline$R^{2}$ & .06 & & & .20 & & & .37 & & & .42 & & \\
\hline \multicolumn{13}{|l|}{ MW-FR outcome: } \\
\hline Intercept & $8.15^{* * *}$ & .52 & 15.54 & $8.44^{* * *}$ & .50 & 16.89 & $7.45^{* * *}$ & .46 & 16.31 & $7.71^{* * *}$ & .45 & 16.99 \\
\hline Gender & $2.26^{* * *}$ & .61 & 3.72 & $1.48^{* *}$ & .60 & 2.47 & $2.35^{* * *}$ & .52 & 4.52 & $1.86^{* *}$ & .53 & 3.48 \\
\hline Region & -.73 & .61 & -1.20 & -.48 & .57 & -.84 & .54 & .55 & .99 & .55 & .53 & 1.04 \\
\hline WIAT-III Essay Composition & & & & $1.32^{* * *}$ & .30 & 4.41 & & & & $.83^{* *}$ & .28 & 2.99 \\
\hline WRAT $_{4}$ Math Computation & & & & & & & $2.07^{* * *}$ & .27 & 7.57 & $1.84^{* * *}$ & .28 & 6.66 \\
\hline$R^{2}$ & .09 & & & .19 & & & 34 & & & .38 & & \\
\hline
\end{tabular}

Note.-WIAT-III = Wechsler Individual Achievement Test (3rd ed.); WRAT4 $=$ Wide Range Achievement Test (4th ed.); MW-WP $=$ Math Writing Word Problem; MW-FR $=$ Math Writing Fractions.

$* p<.05$.

** $p<.01$.

*** $p<.001$. 
of Essay Composition in model 2 accounted for a significant amount of additional variance (14\%), $F(3,151)=12.34, p<.001$. The Math Computation score was then entered into model 3 (with Essay Composition removed) and resulted in a larger percentage of variance explained, as it accounted for an additional $31 \%$ of the variance above model $1, F(3,151)=29.58, p<.001$.

In model 4 for MW-WP, all of the independent variables were significant predictors in the model: WIAT-III Essay Composition $(p<.001)$, WRAT4 Math Computation $(p<.001)$, gender $(p<.047)$, and region $(p<.001)$. The model explained $42 \%$ of the total variance in the MW-WP total score, $F(4,150)=27.45, p<$ .001. Dummy variables were used for gender $($ male $=0$, female $=1$ ) and region (plains $=0$, southwest $=1$ ). Because $z$-scores were used for the writing and mathematics independent variables, the coefficient of 4.03 for the constant represents the expected MW-WP Total Score for males from the plains region that scored at the 5oth percentile on both WIAT-III Essay Composition and WRAT4 Math Computation subtests. When controlling for the other variables, students scoring one standard deviation above the 5oth percentile on the WIAT-III would be expected to score 0.95 points higher on the MW-WP Total Score, and students scoring one standard deviation above the 5oth percentile on WRAT4 Math Computation would score 1.97 points higher. Females were expected to perform 0.99 points higher than males, while students in the southwestern region were expected to score 2.34 points higher than students in the plains region.

Fraction mathematics writing. Results for the MW-FR outcome are also presented in Table 4. Model 1 results revealed that the control variables explained $9 \%$ of the variance in story-writing quality, $F(2,152)=7.31, p<.001$. The addition of Essay Composition in model 2 accounted for a significant amount of additional variance $(10 \%), F(3,151)=11.95, p<.001$. The Math Computation score was then entered into model 3 (with Essay Composition removed) and resulted in a larger percentage of variance explained, as it accounted for an additional $25 \%$ of the variance above model $1, F(3,151)=25.80, p<.001$.

In model 4 for MW-FR, region was not a significant predictor in the model $(p=.301)$, but all of the other independent variables were significant predictors: WIAT-III Essay Composition $(p=.003)$, WRAT4 Math Computation $(p<.001)$, and gender $(p=.001)$. Results presented in model 4 revealed that the independent variables explained $38 \%$ of the variance in the MW-FR Total Score, $F(4,150)=$ $22.60, p<.001$. Because the independent variables used in the MW-FR analysis were the same for the MW-WP analysis; the interpretation of the coefficients for this model are analogous. The coefficient of 7.71 for the intercept represents the expected MW-FR score for a male student from the plains region that scored at the 5oth percentile on both the WIAT-III and WRAT4 subtests. The coefficients indicated that students scoring one standard deviation above the 5oth percentile on WIAT-III Essay Composition would be expected to score 0.82 points higher on the MW-FR Total Score, and students scoring one standard deviation above the 5oth percentile on WRAT4 Math Computation would score 1.84 points higher. Females were expected to perform 1.86 points higher than males. Finally, students in the southwestern region were expected to score 0.55 points higher than students in the plains region when controlling for the other variables, although the coefficient for this variable was not significant. 
Differential Influences of Whole Number Computation and Rational Number Computation Skills

As an exploratory follow-up analysis, we used regression models to examine the influence of whole number computation and rational number computation (i.e., fractions, decimals, and percentages) skill on both of the mathematics-writing tasks. Because this was exploratory, we elected not to include any additional predictors in these models. In these analyses, our goal was simply to examine whether specific mathematics skills (i.e., whole number computation or rational number computation) have the potential to differentially predict specific mathematicswriting outcomes, in order to inform future research. The Whole Number Computation score was calculated from the 20 whole number computation problems from the WRAT4 Math Computation subtest, while Rational Number Computation was calculated from the 15 rational number computation problems from WRAT4 Math Computation. Whole Number Computation and Rational Number Computation were included as independent variables in the model to estimate the unique variance of each of these skills. MW-WP and MW-FR were used as the dependent variable in the models. Results for the two regression models related to question 3 are presented in Table 5 .

Influences on MW-WP. The results presented in model 5 revealed that the independent variables explained $28 \%$ of the variance in the MW-WP Total Score, $F$ $(2,152)=19.81, p<.001$. Whole Number Computation Skill was a significant predictor in the model $(p<.001)$. However, Rational Number Computation Skill was not a significant predictor in the model $(p<.422)$. We cannot reject the null hypothesis that rational number computation skill has no influence on students' ability to respond to the MW-WP assessment. However, we reject the null hypothesis that whole number computation skill does not influence students' mathematicswriting score.

Influences on MW-FR. Similar to model 5, the results presented in model 6 revealed that the independent variables explained $24 \%$ of the variance in the MW-FR Total Score, $F(2,152)=20.78, p<.001$. In contrast to model 3 , both WIAT-III Essay Composition $(p=.006)$ and WRAT 4 Math Computation $(p<.001)$ were significant predictors in the model. Therefore, we reject the null hypothesis that both

Table 5. Hierarchical Multiple Regression Analyses Predicting Mathematics-Writing Scores from Whole-Number Computation Skill and Rational Number Skill

\begin{tabular}{|c|c|c|c|c|c|c|}
\hline \multirow[b]{2}{*}{ Variable } & \multicolumn{3}{|c|}{ Model 5: MW-WP } & \multicolumn{3}{|c|}{ Model 6: MW-FR } \\
\hline & $b$ & $S E$ & $t$ & $b$ & $S E$ & $t$ \\
\hline Constant & $5.47^{* * *}$ & .26 & 22.20 & $8.97^{* * *}$ & .28 & 32.59 \\
\hline Whole-number computation skill & $2.06^{\star * *}$ & .29 & 7.20 & $1.57^{\star * *}$ & .30 & 5.15 \\
\hline Rational number skill & -.09 & .29 & -.32 & $.67^{* *}$ & .30 & 2.22 \\
\hline$R^{2}$ & .28 & & & .24 & & \\
\hline
\end{tabular}


of these skills have no influence on students' ability to respond to the MW-FR assessment. In other words, whole number computation skill and rational number computation skill both contributed significantly to students' MW-FR Total Score.

\section{Discussion}

To explore the relationships among general writing ability, computation skill, and mathematics writing, we interpreted the correlations among the assessments. General writing ability was moderately correlated with mathematics writing for both word problems and fractions. However, the correlations were not large enough to suggest that students can simply transfer their writing skills to mathematicswriting tasks. Although computation skill was more strongly correlated with the mathematics-writing tasks, these correlations were also in the moderate range, suggesting that students may not simply be able to transfer their mathematics skills to mathematics-writing tasks. In fact, the correlations were smaller than correlations between genres found by Graham et al. (2016), who suggested students may not be able to generalize writing knowledge from one genre to another. Moreover, the correlation between the Total Scores for MW-WP and MW-FR was only .48 , suggesting that students' performance on one mathematics-writing task may not be a strong predictor of students' performance on a different mathematicswriting task. Collectively, these findings indicate that students may need to bring different combinations of writing and computation skills to specific mathematicswriting tasks.

To further illustrate this, general writing had only a small correlation with computation skill. This validated our decision to examine the correlations among students' computation skill, writing skills, and subscores of the mathematics-writing assessments related to organization and content. As stated in the Results, general writing ability was more strongly correlated with organization than with content. Alternatively, computation skill was more strongly correlated with content scores than organization scores. In other words, computation and writing skills are unique and appear to contribute to different aspects of mathematics writing.

In the two final hierarchical regression models, writing and computation skills were significant predictors for both mathematics-writing problem types, indicating that as computation and writing skills increased, the outcomes increased. Because we used $z$-scores for both variables, the coefficients were directly interpretable and suggested that increases in computation skill but not writing skill doubled the increases in mathematics-writing scores. The comparison of the hierarchical models also indicates that mathematics and writing both explain unique and significant variance in both outcomes, with the mathematics computation score explaining a larger percentage of the variance than the essay writing score. However, these results must be interpreted cautiously. It is possible that these results are a reflection of the scoring system used for the MW-WP and MW-FR problems, which may have favored computation skill over writing performance. That is, the scoring system allowed students to score more points for mathematics content than for the organization of the writing. Still, it is encouraging that students' computation skill, which is predictive of overall mathematics competence, is captured by the mathematics-writing tasks, and 
the outcomes seem to be more strongly related to computation skills than writing skills.

The regression models also revealed significant contributions of gender and region. The results for gender were expected, as females tend to be better writers than males (Berninger \& Fuller, 1992; Graham, 2006). However, region must be interpreted more cautiously, as only one school district represented each region.

To examine the influence of whole number computation skill and rational number computation skill on mathematic writing, we selected items from the WRAT4 Math Computation that represented whole number computation skill and items that represented rational number computation skill. Stronger whole number computation skill was a significant predictor of whether students would write successfully about word problems and fractions. Interestingly, stronger rational number computation skill only predicted whether students wrote successfully about fractions. It appears that students must have some competence with rational number computation to be able to write about fractions.

\section{Limitations}

Before explaining the implications for research and practice, we note several limitations to the present study. First, the mathematics-writing word problem and fraction prompts were not directly comparable. The maximum scores differed on these assessments, influencing the range of scores and increasing the variance. Therefore, direct comparison of the means was not appropriate, although students' scores on these assessments were moderately correlated $(r=.48)$. The comparability and standardization of scoring for these and other mathematics-writing assessments should be explored in future studies.

Second, we did not have a diverse participant sample. Despite conducting assessments in two distinct regions of the United States, the populations were primarily English-speaking Caucasian students without disabilities. The sample had above-average scores on norm-referenced measures of computation and writing. Future research needs to be conducted to determine whether our findings hold for students with disabilities (i.e., students with writing disabilities, mathematics disabilities, or comorbid writing and mathematics disabilities), English learners, and general lower-performing students.

Third, and specific to the mathematics-writing assessments, the prompt for MW-FR asked participants to identify all of the pseudo-students who made mistakes in the problem but prompted students to "help" only one student. Despite this, more than $70 \%$ of the participants in the sample chose to help (or to attempt to help) more than one pseudo-student. In scoring this assessment, we made the decision to give participants credit for every pseudo-student they helped, rather than to attempt to discern which aspects of their response to score. In other words, participants were given credit for all pseudo-students they helped. In making this choice, we realize the data may not reflect the abilities of all of the participants, as some participants may have limited their answer to one student on the basis of the question prompt, despite having the ability to help additional students. This may have introduced some bias into the analysis. As this was an exploratory study, we were interested in examining and describing participants' actual responses, and we 
were willing to potentially sacrifice some of the measure's validity. That said, the writing prompt and scoring protocols should be revised for this assessment in any future replications of this research.

An additional limitation of the study involved the measurement of the mathematics computation subskills for question 3 (i.e., whole number computation vs. rational number computation). First, the WRAT4 Math Computation is primarily a computation measure, so almost all questions asked students to calculate an answer using addition, subtraction, multiplication, and division. The items representing whole number computation provide a survey of computational skill, but not all operations or problem types are represented. The same is true for rational number computation items on WRAT 4 Math Computation. The test does not assess underlying concepts related to fractions or decimals, and not all rational number computation operations and problem types are represented. Second, a potential confound in the WRAT4 was related to the order of these subskills. The items on WRAT4 progress from less difficult to more difficult, and the majority of whole number computation problems are presented earlier in the test before the rational number computation items. Because this was a timed test, some students may have not had the opportunity to solve all rational number computation items before administration of the test finished.

\section{Implications for Research and Practice}

In terms of research, we need to develop and pilot mathematics-writing prompts in other mathematics content areas. We selected word problems and fractions because of the prevalence of these skills in standards and textbooks, but students should demonstrate mathematics-writing competency in other content areas. Researchers should evaluate mathematics-writing prompts on high-stakes assessments and create and pilot similar prompts. We need to develop scoring rubrics for such mathematics-writing prompts and understand how the rubrics can provide accurate information about writing ability (i.e., organization) and mathematics performance (i.e., content). Additionally, researchers should design rubrics of mathematics writing that can assess grammar, syntax, mechanics, and sentence formation.

Researchers also need to evaluate the mathematics writing of students at other grade levels. We selected fourth grade because fourth grade is typically the first year students are expected to write on high-stakes assessments. We wanted to assess students who had developed basic writing skill but who were still developing writing proficiency and mathematics proficiency. We would be interested in learning whether the pattern of results is the same with younger writers as well as writers at middle school and high school. We also need to evaluate the mathematics writing of more diverse samples from other regions of the United States. Researchers should also assess the general writing ability and computation skill of students in more depth and investigate the connections to mathematics writing. We selected the WIAT-III Essay Composition and WRAT4 Math Computation because of the ease of administration and scoring, but we realize these measures do not provide a holistic picture of writing or mathematics performance.

In terms of practice, we conducted this exploratory study to gather data about a starting point for developing an intervention focused on teaching mathematics 
writing. Because high-stakes assessments may require students to write about mathematics, and because the results from this exploratory study indicate wide variability with mathematics-writing scores, specific interventions for students may be necessary. This may be especially true for students with lower general writing ability and lower computation skill. The current research base provides suggestions for mathematics-writing activities, but we have no empirical research that compares mathematics-writing interventions. While several general writing strategies (e.g., Self-Regulated Strategy Development; Mason, Harris, \& Graham, 2011) provide evidence for improving general writing ability, from this study we learned that computation skill is necessary for mathematics writing. For mathematics writing, we cannot teach students how to write about mathematics in a strictly procedural way. There is much more to mathematics writing, including organization and content, but there are likely other contributing factors. If students complete mathematics-writing interventions, researchers should also investigate whether improved mathematics writing positively influences general writing ability.

Based on the results of this study, we (a) suggest identifying students early for intervention. Students with lower general writing and lower computation skill typically struggle with mathematics writing. So, identifying these students early and providing appropriate intervention may improve mathematics writing. We (b) propose tailoring interventions based on student profiles. Teachers should conduct an assessment of general writing ability and computation skill before delivering any mathematics intervention. Students with deficits in both writing and mathematics may require differential support compared to students with a deficit in only on area.

\section{Conclusion}

Before conducting the present study, we outlined three assumptions related to mathematics writing based on previous mathematics-writing assessments. Our first assumption was that students have necessary writing skill. We analyzed writing skill using WIAT-III Essay Composition, and student scores ranged from o to 19 (maximum score $=20$ ), which indicates that some students in our sample had the necessary writing skills whereas others did not. Our second assumption was that students can transfer their knowledge of writing to mathematics-writing tasks and communicate their knowledge of mathematical concepts and procedures in writing. We learned that students with stronger writing skill do indeed transfer that skill to write more effectively about mathematics, and some students can communicate about mathematics using writing. Mathematics writing is also significantly correlated with computation skill. However, the correlations between writing tasks, mathematics-writing tasks, and computation skill were only in the moderate range. Additionally, students demonstrated wide variability in mathematics writing. This suggests that students need to bring different skills to bear on different tasks. Thus, students may benefit from instruction in how to write for specific mathematics-writing tasks. We discuss specific details of mathematics writing in another manuscript (Hebert \& Powell, 2016). Our third assumption was that writing about mathematics is an indicator of mathematics ability. As stated, we learned that computation skill 
is correlated with mathematics writing, but future research is necessary to investigate this connection further.

In sum, there are strong correlations between general writing ability and mathematics writing, as well as computation skill and mathematics writing. Students who are stronger essay writers write better about mathematics. Also, students with better computation skill write better about mathematics. To inform future interventions related to mathematics writing, researchers and educators might wish to assess the background knowledge of the students in order to efficiently and effectively design mathematics-writing instruction.

\section{Appendix}

Table A1. Mathematics-Writing Means, Standard Deviations, and Coefficient Alpha Correlations

\begin{tabular}{|c|c|c|c|c|c|c|}
\hline Measure & $\begin{array}{l}\text { Rubric } \\
\text { Subset }\end{array}$ & Item & $M$ & $(S D)$ & $\begin{array}{l}\text { Corrected } \\
\text { Item-Total } \\
\text { Correlation }\end{array}$ & $\begin{array}{c}\text { Cronbach's } \alpha \\
\text { If Item } \\
\text { Deleted }\end{array}$ \\
\hline MW-WP & Organization & Introduction & .026 & $(.159)$ & -.010 & .733 \\
\hline MW-WP & Organization & Conclusion & .084 & $(.278)$ & .102 & .730 \\
\hline MW-WP & Organization & Paragraphs & .865 & $(.511)$ & .499 & .701 \\
\hline MW-WP & Organization & Transition & .819 & $(1.077)$ & .385 & .731 \\
\hline MW-WP & Content & A correct math & .226 & $(.419)$ & .103 & .733 \\
\hline MW-WP & Content & A unnecessary step & .032 & $(.177)$ & .082 & .730 \\
\hline MW-WP & Content & A elaboration & .026 & $(.159)$ & .110 & .729 \\
\hline MW-WP & Content & B correct math & .032 & $(.177)$ & .004 & .733 \\
\hline MW-WP & Content & B incorrect step & .490 & $(.501)$ & .398 & .710 \\
\hline MW-WP & Content & B elaboration & .245 & $(.432)$ & .358 & .714 \\
\hline MW-WP & Content & C correct step & .245 & $(.432)$ & .263 & .722 \\
\hline MW-WP & Content & $\mathrm{C}$ incorrect answer & .368 & $(.484)$ & .432 & .707 \\
\hline MW-WP & Content & C elaboration & .323 & $(.469)$ & .277 & .721 \\
\hline MW-WP & Content & C corrected answer & .413 & $(.494)$ & .451 & .705 \\
\hline MW-WP & Content & D1 incorrect numbers & .245 & $(.432)$ & .437 & .708 \\
\hline MW-WP & Content & D1 corrected numbers & .245 & $(.432)$ & .463 & .706 \\
\hline MW-WP & Content & $\mathrm{D}_{2}$ incorrect place value & .258 & $(.439)$ & .211 & .726 \\
\hline MW-WP & Content & D2 elaboration & .168 & $(.375)$ & .206 & .725 \\
\hline MW-WP & Content & D2 corrected place value & .148 & $(.357)$ & .289 & .720 \\
\hline MW-WP & Content & $\mathrm{D}_{3}$ incorrect subtraction & .032 & $(.177)$ & .082 & .730 \\
\hline MW-WP & Content & D3 elaboration & .007 & $(.080)$ & -.016 & .732 \\
\hline MW-WP & Content & D4 correct subtraction & .226 & $(.419)$ & 399 & .712 \\
\hline MW-WP & Content & D5 correct overall answer & .226 & $(.419)$ & .439 & .709 \\
\hline MW-FR & Organization & Introduction & .597 & $(.086)$ & .180 & .696 \\
\hline MW-FR & Organization & Conclusion & .052 & $(.250)$ & .199 & .682 \\
\hline MW-FR & Organization & Paragraphs & .857 & $(.690)$ & .488 & .647 \\
\hline MW-FR & Organization & Transition & .240 & $(.549)$ & .304 & .671 \\
\hline MW-FR & Content & A mistake Alex & .533 & $(.501)$ & .356 & .666 \\
\hline MW-FR & Content & A mistake Bo & .890 & $(.314)$ & .319 & .674 \\
\hline MW-FR & Content & A mistake Cole & .065 & $(.392)$ & .272 & .675 \\
\hline MW-FR & Content & A mistake Deb & .136 & $(.247)$ & -.135 & .697 \\
\hline MW-FR & Content & A no mistake Deb & .136 & $(.344)$ & .153 & .684 \\
\hline MW-FR & Content & A mistakes Alex, Bo, Cole & .487 & $(.501)$ & .377 & .686 \\
\hline MW-FR & Content & B identifies student to help & .643 & $(.481)$ & .304 & .672 \\
\hline MW-FR & Content & Alex has 5 parts & .071 & $(.258)$ & .309 & .676 \\
\hline MW-FR & Content & Alex shaded 3 of 5 parts & .084 & $(.279)$ & .183 & .682 \\
\hline
\end{tabular}


Table A1. (Continued)

\begin{tabular}{|c|c|c|c|c|c|c|}
\hline Measure & $\begin{array}{l}\text { Rubric } \\
\text { Subset }\end{array}$ & Item & $M$ & $(S D)$ & $\begin{array}{l}\text { Corrected } \\
\text { Item-Total } \\
\text { Correlation }\end{array}$ & $\begin{array}{c}\text { Cronbach's } \alpha \\
\text { If Item } \\
\text { Deleted }\end{array}$ \\
\hline MW-FR & Content & Alex incorrect parts unequal & .253 & $(.436)$ & .352 & .668 \\
\hline MW-FR & Content & Alex written correction & .182 & $(.387)$ & .323 & .672 \\
\hline MW-FR & Content & Alex drawn correction & .084 & $(.279)$ & .038 & .690 \\
\hline MW-FR & Content & Bo has 8 parts instead of 5 & .474 & $(.501)$ & .114 & .689 \\
\hline MW-FR & Content & Bo shaded 3 of 8 parts & .448 & $(.499)$ & .242 & .677 \\
\hline MW-FR & Content & Bo has incorrect denominator & .429 & $(.496)$ & .302 & .672 \\
\hline MW-FR & Content & Bo written correction & .331 & $(.472)$ & .074 & .692 \\
\hline MW-FR & Content & $\begin{array}{l}\text { Bo drawn correction } \\
\text { Cole has incorrect }\end{array}$ & .110 & $(.314)$ & -.052 & .695 \\
\hline MW-FR & Content & denominator & .338 & $(.474)$ & .293 & .673 \\
\hline MW-FR & Content & Cole shaded 5 parts instead of 3 & .273 & $(.447)$ & .239 & .678 \\
\hline MW-FR & Content & Cole has incorrect numerator & .266 & $(.443)$ & .310 & .672 \\
\hline MW-FR & Content & Cole written correction & .273 & $(.447)$ & .298 & .673 \\
\hline MW-FR & Content & Cole drawn correction & .058 & $(.235)$ & -.003 & .690 \\
\hline
\end{tabular}

Note - MW-WP $=$ Math Writing Word Problem; MW-FR $=$ Math Writing Fractions.

\section{Note}

This research was supported by the Scholarly Enhancement Program at the University of Nebraska-Lincoln and funds from the University of Texas at Austin. We specifically thank Sally Fluhler, Mallory Johnsen, and Julia Roehling for assistance with data collection and scoring. We also extend thanks to the teachers and students who participated in this project. Statements do not reflect the position or policy of the university, schools, or persons, and no official endorsement should be inferred. Sarah R. Powell is an assistant professor in the Department of Special Education, University of Texas at Austin; Michael A. Hebert is an assistant professor in the Department of Special Education and Communication Disorders, University of Nebraska-Lincoln. Correspondence concerning this article should be addressed to Sarah R. Powell, 1 University Station D5300, Austin, TX 78712; e-mail: srpowell@austin.utexas.edu.

\section{References}

Baxter, J. A., Woodward, J., \& Olson, D. (2005). Writing in mathematics: An alternative form of communication for academically low-achieving students. Learning Disabilities Research and Practice, 20, 119-135. doi:10.1111/j.1540-5826.2005.00127.x

Berninger, V., \& Fuller, F. (1992). Gender differences in orthographic, verbal, and compositional fluency: Implications for assessing writing disabilities in primary grade children. Lournal of School Psychology, 30, 363-382. doi:10.1016/0022-4405(92)90004-O

Bicer, A., Capraro, R. M., \& Capraro, M. M. (2013). Integrating writing into mathematics classroom to increase students' problem solving skills. International Online Journal of Educational Sciences, 5, 361-369.

Bossé, M. J., \& Faulconer, J. (2008). Learning and assessing mathematics through reading and writing. School Science and Mathematics, 108, 8-19. doi:10.1111/j.1949-8594.2008.tb17935.x

Breaux, K. C. (2010). Wechsler Individual Achievement Test-Third edition: Technical manual. Bloomington, MN: Pearson.

Burns, M. (2004). Writing in math. Educational Leadership, 62(2), 30-33.

Bynner, J., \& Parsons, S. (1997). Numeracy and employment. Education and Training, 39, 43-51. doi:10.1108/00400919710164125 
Carter, S. (2009). Connecting mathematics and writing workshop: It's kinda like ice skating. Reading Teacher, 62, 606-610. doi:10.1598/RT.62.7.7

Claessens, A., Duncan, G., \& Engel, M. (2009). Kindergarten skills and fifth-grade achievement: Evidence from the ECLS-K. Economics of Education Review, 28, 415-427. doi:10.1016 /j.econedurev.2008.09.003

Coffman, W. (1966). On the validity of essay tests of achievement. Lournal of Educational Measurement, 3, 151-156.

Correnti, R., Matsumara, L. C., Hamilton, L., \& Wang, E. (2013). Assessing students' skills at writing analytically in response to texts. Elementary School Journal, 114, 142-177. doi:10.1086 1671936

Cross, D. I. (2009). Creating optimal mathematics learning environments: Combining argumentation and writing to enhance achievement. International Journal of Science and Mathematics Education, 7, 905-930. doi:10.1007/s10763-008-9144-9

Driver, M. K., \& Powell, S. R. (2015). Symbolic and nonsymbolic equivalence tasks: The influence of symbols on students with mathematics difficulty. Learning Disabilities Research and Practice, 30, 127-134. doi:10.1111/ldrp.12059

Ediger, M. (2006). Writing in the mathematics curriculum. Journal of Instructional Psychology, $33,120-123$.

Fello, S. E., \& Paquette, K. R. (2009). Talking and writing in the classroom. Mathematics Teaching in the Middle School, 14, 410-414.

Fernsten, L. A. (2007). A writing workshop in mathematics: Community practice of content discourse. Mathematics Teacher, 101, 273-278.

Fukawa-Connelly, T., \& Buck, S. (2010). Using portfolio assignments to assess students' mathematical thinking. Mathematics Teacher, 103, 649-654.

Gilbert, J., \& Graham, S. (2010). Teaching writing to elementary students in grades 4-6: A national survey. Elementarv School Journal, 110, 494-518. doi:10.1086/651193

Graham, S. (2006). Writing. In P. A. Alexander \& P. H. Winne (Eds.), Handbook of educational psychology (pp. 457-477). Mahwah, NJ: Erlbaum.

Graham, S., Hebert, M., Sandbank, M. P., \& Harris, K. (2016). Assessing the writing achievement of young struggling writers: Application of generalizability theory. Learning Disability Quarterlv, 39, 72-82. doi:10.1177/0731948714555019

Graham, S., McKeown, D., Kiuhara, S., \& Harris, K. R. (2012). A meta-analysis of writing instruction for students in the elementary grades. Lournal of Educational Psychology, 104, 879-896. doi:10.1037/aoo29185

Graham, S., \& Perin, D. (2007). A meta-analysis of writing instruction for adolescent students. Lournal of Educational Psychology, 99, 445-476. doi:10.1037/0022-0663.99.3.445

Hebert, M. A., \& Powell, S. R. (2016). Examining fourth-grade mathematics writing: Features of organization, mathematics vocabulary, and mathematical representations. Reading and Writing: An Interdisciplinary Iournal, 29, 1511-1537. doi:10.1007/s11145-016-9649-5

Hooper, S. R., Roberts, J. E., Nelson, L., Zeisel, S., \& Fannin, D. K. (2010). Preschool predictors of narrative writing skills in elementary school children. School Psychology Quarterly, 25, 1-12. doi:10.1037/aoo18329

Hough, T. M., Hixson, M. D., Decker, D., \& Bradley-Johnson, S. (2012). The effectiveness of an explicit instruction writing program for second graders. Iournal of Behavioral Education, 21, 163-174. doi:10.1007/s10864-012-9146-o

How, K., \& Larkin, R. F. (2013). Descriptive writing in primary school: How useful are linguistic predictors of reading? Lournal of Educational Research, 106, 360-371. doi:10.1080/00330671.2012 .753864

Huang, J. (2008). How accurate are ESL students' holistic writing scores on large-scale assessments? A generalizability theory approach. Assessing Writing, 13, 201-218. doi:10.1016/j.asw .2008.10.002

Jenkins, J. R., Johnson, E., \& Hileman, J. (2004). When is reading also writing: Sources of individual differences on the new reading performance assessments. Scientific Studies of Reading, 8, 125-151. doi:10.1207/s1532799Xssro802_2 
Jordan, N. C., Kaplan, D., \& Hanich, L. B. (2002). Achievement growth in children with learning difficulties in mathematics: Findings of a two-year longitudinal study. Lournal of Educational Psvchologv, 94, 586-597. doi:10.1037//0022-0663.94.3.586

Juzwik, M. M., Curcic, S., Wolbers, K., Moxley, K. D., Dimling, L. M., \& Shankland, R. K. (2006). Writing into the 21st century: An overview of research on writing, 1999 to 2004. Written Communication, 23, 451-476. doi:10.1177/0741088306291619

Kostos, K., \& Shin, E. (2010). Using math journals to enhance second graders' communication of mathematical thinking. Early Childhood Education Journal, 38, 223-231. doi:10.1007/s10643 -010-0390-4

Lee, J. (2012). College for all: Gaps between desirable and actual P-12 math achievement trajectories for college readiness. Educational Researcher, 41, 43-55. doi:10.3102/o013189X11432746

Lienemann, T. O., Graham, S., Leader-Janssen, B., \& Reid, R. (2006). Improving the writing performance of struggling writers in second grade. Iournal of Special Education, 40, 66-78. doi:10.1177/00224669060400020301

Lynch, S. D., \& Bolyard, J. J. (2012). Mathematical discourse in writing. Mathematics Teaching in the Middle School, 17, 486-492. doi:10.5951/mathteacmiddscho.17.8.0486

Lynch-Davis, K. (2011). Responding to journal writing in the middle grades mathematics classroom. National Teacher Education Journal, 4, 93-96.

Mabbott, D. J., \& Bisanz, J. (2008). Computational skills, working memory, and conceptual knowledge in older children with mathematics learning disabilities. Journal of Learning Disabilities, 41, 15-28. doi:10.1177/0022219407311003

Mason, L. H., Harris, K. R., \& Graham, S. (2011). Self-regulated strategy development for students with writing difficulties. Theory into Practice, 50, 20-27. doi:10.1080/00405841.2011.534922

McCarthy, D. S. (2008). Communication in mathematics: Preparing preservice teachers to include writing in mathematics teaching and learning. School Science and Mathematics, 108, 334-340. doi:10.1111/j.1949-8594.2008.tb17846.x

National Center for Education Statistics. (2012). The Nation's Report Card: Writing 2011 (NCES 2012-470). Washington, DC: U.S. Department of Education.

National Council of Teachers of Mathematics. (2000). Principles and standards for school mathematics. Reston, VA: Author.

National Governors Association Center for Best Practices \& Council of Chief State School Officers. (2010). Common Core State Standards for mathematics. Washington, DC: Author.

Psychological Corp. (2009). Wechsler Individual Achievement Test-Third edition. San Antonio, TX: Author.

Sanders, C. V. (2009). Exploring and writing geometry. Mathematics Teacher, 102, 432-439.

Seo, B.-I. (2009). Understanding the affects of audience on mathematical writing. School Science and Mathematics, 109, 116-127. doi:10.1111/j.1949-8594.2009.tb17944.x

Shanahan, T. (2006). Relations among oral language, reading, and writing development. In C. A. MacArthur, S. Graham, \& J. Fitzgerald (Eds.), Handbook of writing research (pp. 171-183). New York: Guilford.

Sherman, J., \& Bisanz, J. (2009). Equivalence in symbolic and nonsymbolic contexts: Benefits of solving problems with manipulatives. Iournal of Educational Psychology, 101, 88-100. doi: $10.1037 /$ aoo 13156

StataCorp. (2011). Stata Statistical Software: Release 12. College Station, TX: StataCorp. LP.

Swanson, H. L., Jerman, O., \& Zheng, X. (2008). Growth in working memory and mathematical problem solving in children at risk and not at risk for serious math difficulties. Journal of Educational Psychology, 100, 343-379. doi:10.1037/0022-0663.100.2.343

Thompson, L. S. (2010). Writing to communication mathematically in the elementary school classroom. Ohio Journal of School Mathematics, 61, 36-44.

Van de Walle, J. A., Karp, K. S., \& Bay-Williams, J. M. (2013). Elementary and middle school mathematics: Teaching developmentally (8th ed.). Boston: Pearson.

Wakely, M. B., Hooper, S. R., de Kruif, R. E. L., \& Swartz, C. (2006). Subtypes of written expression in elementary school children: A linguistic-based model. Developmental Neuropsvchologv, 29, 125-159. doi:10.1207/s15326942dn2901_7 
Wilcox, B., \& Monroe, E. E. (2011). Integrating writing and mathematics. Reading Teacher, 64, 521-529. doi:10.1598/RT.64.7.6

Wilkinson, G. S., \& Robertson, G. J. (2006). Wide Range Achievement Test: Fourth edition. Lutz, FL: PAR.

Yang, D.-C. (2005). Developing number sense through mathematical diary writing. Australian Primary Mathematics Classroom, 10(4), 9-14. 